\title{
Optimal Design of a Magnetorheological Haptic Gripper Reflecting Grasping Force and Rolling Moment from Telemanipulator
}

\author{
원격조작기의 악력과 회전모멘트를 고려한 \\ $\mathrm{MR}$ 햅틱 그리퍼의 최적설계
}
Quoc-Hung Nguyen, Jong-Seok Oh and Seung-Bok Choi 구 오 흥*.오 종 석*.최 승 복

(Received March 21, 2012 ; Accepted April 17, 2012)

Key Words : Magnetorheological Fluid(MR 유체), MR Brake(MR 브레이크), Haptic Gripper(햅틱 그리퍼), Telemanipulator(원격조작기)

\begin{abstract}
In this work, the configuration of a haptic gripper featuring magnetorheological(MR) brakes is proposed and an optimal design of the MR brakes for the haptic griper is performed considering the required braking torque, the uncontrollable torque(zero-field friction torque) and mass of the brakes. Several configurations of MR brake is proposed such as disc-type, serpentine-type and hybrid-type. After the configurations of the MR brakes are proposed, braking torque of the brakes is analyzed based on Bingham rheological model of the MR fluid. The zero-field friction torque of the MR brakes is also analyzed. An optimization procedure based on finite element analysis integrated with an optimization toolbox is developed for the MR brakes. The purpose of the optimal design is to find optimal geometric dimensions of the MR brake structure that can produce the required braking torque and minimize the mass of the MR brakes. In addition, the uncontrollable torque of the MR brakes is constrained to be much smaller than the required braking torque. Based on the developed optimization procedure, optimal solution of the proposed MR brakes are achieved and the best MR brake is determined. The working performance of the optimized MR brake is then investigated.
\end{abstract}

\section{요 약}

이 연구에서는 MR 브레이크를 이용하는 새로운 형태의 햅틱 그리퍼를 제안하였다. 이를 위 하여, 다양한 형태의 MR 브레이크를 고려한 뒤, 각 MR 브레이크의 제동 토크와 점성 마찰토크 를 빙햄 모델에 기반하여 분석하였다. $\mathrm{MR}$ 브레이크의 최적설계를 위해 유한요소법과 최적화 toolbox를 통합한 새로운 알고리즘이 고안되었으며, 점성 마찰토크는 필요 제동 토크보다 작도 록 구속조건을 설정하였다. 이러한 최적 설계 알고리즘을 통하여 적절한 제동 토크를 시스템에

† 교신저자; 정회원, 인하대학교

E-mail : seungbok@inha.ac.kr

Tel : (032)860-7319, Fax : (032)868-1716

* 인하대학교 대학원 기계공학과 


\section{부하할 수 있으며 무게가 최소화된 MR 브레이크를 설계할 수 있었다. 그리고 최적 설계된 MR 브레이크의 성능 또한 고찰하였다.}

\section{Introduction}

Recently, force feedback techniques have been in use to increase the effectiveness of human-machine interfaces. The applications range from biomedicine to computer games and virtual reality devices such as virtual rehabilitation. In robotics, the well-known concept of "tele-presence" is based on the force feedback techniques. The tele-presence is defined as the ideal of sensing sufficient information about the tele-operator and task environment, and communicating this to the human operator in a sufficient natural way, that the operator feels physically present at the remote site ${ }^{(1)}$. Such a system is often referred to as a robotic master-slave system. This allows the operator to perform tasks in hazardous or distant environments by knowledgeably guiding the robot slave from a safe distant location. For such operations to be successful it is necessary to virtually immerse the human operator in the remote environment through haptic feedback, otherwise the manipulation requires too much effort and becomes slow and imprecise ${ }^{(2)}$. The slave in the tele-operation system is usually a manipulator consisting of a 3-D positional system, a 3-D orientation system which is usually a mechanical wrist and an end-effecter. There have been several researches on developing haptic interfacing system for robot manipulators such as haptic arm exoskeleton $^{(3,4)}$, haptic wrist $^{(5,6)}$, haptic glove $^{(7 \sim 9)}$, haptic-fingered hand ${ }^{(10 \sim 12)}$, haptic master ${ }^{(13)}$. Despite of many researches on haptic devices for robot manipulator, commercial application of such haptic systems are still limited. The main reason is that these haptic systems are somewhat complex which results in the high cost for manu- facturing and control of such devices. In many practical applications such as moving work pieces in automatic manufacturing, assembling and dissembling workshop, the two most important feedback parameters are the grasping force and the rolling torque. However, researches on development of such a haptic device are still very rare.

The main contribution of this research work is to develop a haptic gripper that can feedback grasping force and rolling torque from the slave manipulator to the operator. The haptic griper is featuring two MR brakes. After introducing configuration of the haptic griper, several configurations of MR brakes for the haptic gripper are considered. The optimal design of the MR brakes is then performed considering the required braking torque, the uncontrollable torque and the mass of the MR brakes. The optimal solutions for the MR brakes are then obtained and the optimized MR brake is identified. The working performance of the optimized MR brake is then investigated.

\section{Haptic Gripper Featuring MR Brake}

In order to feedback the grasping force and rolling torque from the slave to the master-operator, a load-cell and a torque sensor is attached to the slave gripper, the signal from these sensors are fed to the MR haptic gripper shown in Fig. 1. As shown in the figure, the haptic gripper consists of two MR brakes: the grasping and rolling MR brake. The shaft of rolling MR brake is fixed to the body of the haptic griper while its housing is attached the master manipulator. The shaft of the grasping MR brake is connected to the gear 2 while its housing is fixed to the gripper body. The gear 2 externally mates with the gear 1 . On the gear $1 \& 2$, the two gripping 
handles are respectively attached. By controlling the applied current of the MR brakes according to the signals from the slave sensors, the grasping force and rolling torque from the slave can be reflected to the master-operator.

\section{MR Brake for the Haptic Gripper}

In this section, several configurations of MR brake are proposed for the haptic gripper. Figure 2(a) shows a disc-type rotary MR brake. In this configuration, the rotor is thin and the MR fluid is energized at the end-faces of the rotor. This is also the simplest type of MR brakes. The second type of MR brake is the drum one. In this configuration, the rotor is much thicker and the MR fluid is energized at the outer radius of the rotor. This type of MR brake is not popular because of its low braking torque and incompact size. In order to increase braking torque while the size of the brake is kept compact, a serpentine drum-type of MR brake was proposed ${ }^{(14)}$. Figure 2(b) shows a configuration of serpentine drum-type MR brake used in this study. As shown in Fig. 2(b), by using the nonmagnetic partitions, the magnetic flux of the brake is forced to go in a serpentine line. With this type of MR brake, the magnetic flux density across the active MR fluid can be maximized and distributed equally along the outer face of the rotor. Figure 2(c) shows the hybrid configuration of a MR brake. This configuration is a

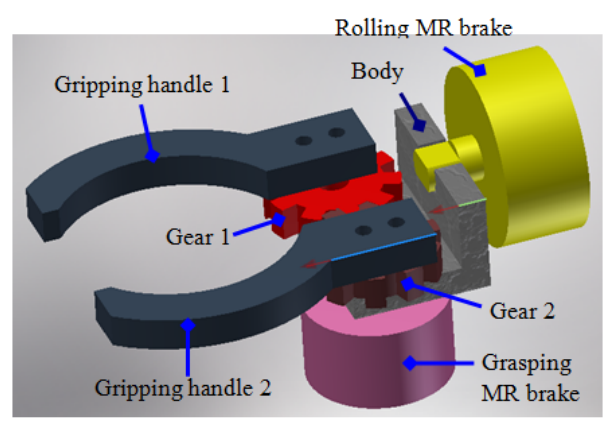

Fig. 1 Configuration of the proposed haptic gripper combination of disc-type and drum-type MR brake. As shown in the figure, when two counter currents are applied to the coils, a mutual magnetic circuit is generated as shown in the figure. This mutual magnetic circuit results in an induced stress of MR fluid in both the annular gap and radial gap(end-face gap) between the rotor and the stator. The induced stress generates a controllable braking torque of the MR brake.

\section{Optimal Design of MR Brakes for the Haptic Gripper}

In this section, the optimal design of MR brakes for the haptic gripper is performed. In order to have a true reflection of the rolling torque and grasping force to the slave to the master-operator, the maximum torque generated by the MR brake should be large enough compared to the available efforts generated by the master operators. In this study, the maximum grasping force reflected to the master-operator is set by 40 $\mathrm{N}$. The distance from the center of the gears to the efforts from the operator is set by $0.1 \mathrm{~m}$. By neglecting of frictional force, required torque of the grasping MR brake is $4 \mathrm{Nm}$. For convenience in design and manufacturing, the required torque of the rolling brake is also set by $4 \mathrm{Nm}$. In addition, in order to have a true reflection of the forces from the slave, the uncontrollable torque of the MR brakes should be much smaller than the required torque. In this study, the uncontrollable torque is constrained to be smaller than $0.02 \mathrm{Nm}$. By neglecting the mechanical friction, the friction of MR fluid at the outer cylindrical face of the disc and applying the Bingham rheological model for MR fluid, the braking and uncontrollable torque of the disc-type brake can be respectively determined by ${ }^{(6)}$

$$
T_{d}=\frac{\pi \mu_{d} R_{d o}^{4}}{d_{d}}\left[1-\left(\frac{R_{d i}}{R_{d o}}\right)^{4}\right] \Omega+\frac{4 \pi \tau_{y d}}{3}\left(R_{d o}^{3}-R_{d i}^{3}\right)
$$




$$
\begin{aligned}
& T_{d 0}=\frac{\pi \mu_{0} R_{d o}^{4}}{d_{d}}\left[1-\left(\frac{R_{d i}}{R_{d o}}\right)^{4}\right] \Omega+\frac{4 \pi \tau_{y 0}}{3}\left(R_{d o}^{3}-R_{d i}^{3}\right) \\
& +2 \pi R_{d o}^{2} t_{d}\left(\tau_{y 0}+\mu_{0} \frac{\Omega R_{d o}}{d_{d}}\right)
\end{aligned}
$$

where $R_{d i}$ and $R_{d o}$ are the inner and outer radius of the disc, $d_{d}$ is the gap size of the MR duct

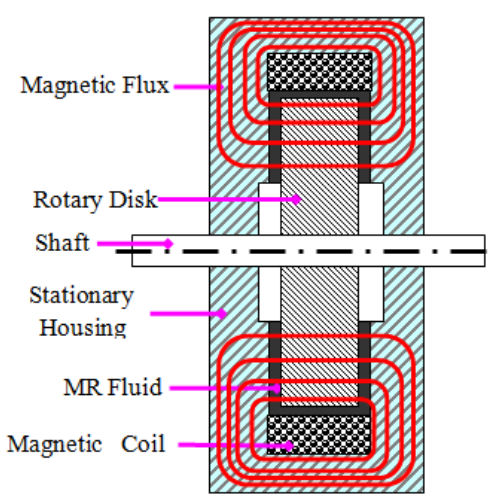

(a) Disc-type MR brake

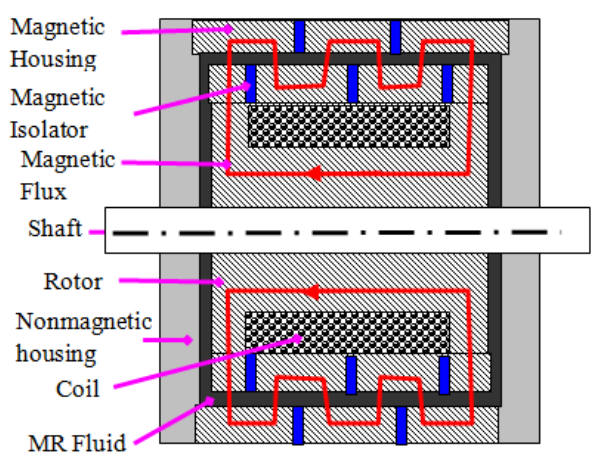

(b) Serpentine drum-type MR brake

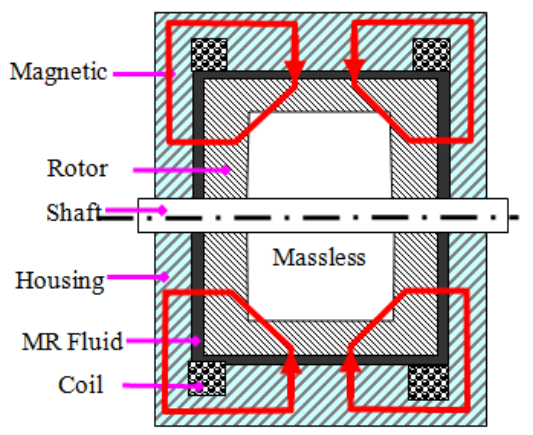

(c) Hybrid-type MR brake

Fig. 2 MR brakes for haptic gripper between the disc and the housing, $t_{d}$ is the thickness of the disc. $\Omega$ is the angular velocity of the rotor. $\mu_{d}$ is the post yield viscosity and $t_{y d}$ is the yield stress of the MR fluid in the duct end-face ducts of the brake. $t_{y d}$ and $\mu_{d}$ are fluidproperties, their values depend on the exerted magnetic flux density across the ducts of MR fluid. $t_{y 0}$ and $\mu_{0}$ are the zero-field yield stress and post yield viscosity of the MR fluid.

For the serpentine type of MR brake shown in Fig. 2(b), the braking torque and the zero-field torque can be respectively determined by ${ }^{(6,14)}$

$$
\begin{aligned}
& T_{s}=\frac{\pi \mu_{0} R_{s o}^{4}}{d_{0}}\left[1-\left(\frac{R_{s i}}{R_{s o}}\right)^{4}\right] \Omega+\frac{4 \pi \tau_{y 0}}{3}\left(R_{s o}^{3}-R_{s i}^{3}\right) \\
& +2 \pi R_{s o}^{2} L_{s}\left(\tau_{y s}+\mu_{s} \frac{\Omega R_{s o}}{d_{s}}\right) \\
& T_{s 0}=\frac{\pi \mu_{0} R_{s o}^{4}}{d_{0}}\left[1-\left(\frac{R_{s i}}{R_{s o}}\right)^{4}\right] \Omega+\frac{4 \pi \tau_{y 0}}{3}\left(R_{s o}^{3}-R_{s i}^{3}\right) \\
& +2 \pi R_{s o}^{2} L_{s}\left(\tau_{y 0}+\mu_{0} \frac{\Omega R_{s o}}{d_{s}}\right)
\end{aligned}
$$

where $R_{s i}$ and $R_{s o}$ are the inner and outer radius of the rotor, $d_{s}$ and $d_{0}$ are respectively the gap size of the annular MR duct and the end-face duct between the disc and the housing, and $L_{s}$ is the effective length of the annular duct. $\mu_{s}$ and $t_{y s}$ are respectively the post yield viscosity and the yield stress of the MR fluid in the annular duct of the brake which depends on exerted magnetic flux density across the duct.

In case of the hybrid type MR brake shown in Fig. 2(c), both the MR fluid in the annular duct and the end-face duct are exerted by the magnetic field, therefore the braking force and the zero-field torque can be respectively determined as follows ${ }^{(6)}$

$$
\begin{aligned}
& T_{h}=\frac{\pi \mu_{e} R_{h o}^{4}}{d_{h e}}\left[1-\left(\frac{R_{h i}}{R_{h o}}\right)^{4}\right] \Omega+\frac{4 \pi \tau_{y e}}{3}\left(R_{h o}^{3}-R_{h i}^{3}\right) \\
& +2 \pi R_{h o}^{2} L_{h}\left(\tau_{y a}+\mu_{a} \frac{\Omega R_{h o}}{d_{h a}}\right)
\end{aligned}
$$




$$
\begin{aligned}
& T_{h}=\frac{\pi \mu_{0} R_{h o}^{4}}{d_{h e}}\left[1-\left(\frac{R_{h i}}{R_{h o}}\right)^{4}\right] \Omega+\frac{4 \pi \tau_{y 0}}{3}\left(R_{h o}^{3}-R_{h i}^{3}\right) \\
& +2 \pi R_{h o}^{2} L_{h}\left(\tau_{y 0}+\mu_{0} \frac{\Omega R_{h o}}{d_{h a}}\right)
\end{aligned}
$$

In the above, $R_{h i}$ and $R_{h o}$ are the inner and outer radius of the rotor of the hybrid MR brake, $d_{h e}$ and $d_{h a}$ are respectively the gap size of the annular MR duct and the end-face duct of the brake and $L_{h}$ is the effective length of the annular duct. $\mu_{e}$ and $\mu_{a}$ are respectively the post yield viscosity of the active MR fluid in the end-face and the annular duct. $t_{y e}$ and $t_{y a}$ are the yield stress of the active MR fluid in the end-face and annular duct, respectively. $\mu_{e}, \mu_{a}, t_{y e}$ and $t_{y a}$ are functions of the exerted magnetic flux density across the ducts.

The mass of the MR brakes can be approximately calculated by

$$
m_{b}=V_{r} \rho_{r}+V_{h} \rho_{h}+V_{s} \rho_{s}+V_{M R} \rho_{M R}
$$

where $V_{r}, V_{h}, V_{s}$ and $V_{M R}$ are respectively the volume of the rotor, the housing, the shaft and the MR fluid of the brake. There parameters are functions of geometric dimensions of the MR brake structures. $\rho_{r}, \rho_{h}, \rho_{s}$ and $\rho_{M R}$ are the density of the rotor, the housing, the shaft and the MR fluid, respectively.

From the above, the optimization problem of the MR brakes can be summarized as follows: Find the optimal value of significant geometric dimensions of the MR brakes so that the maximum braking torque calculated by Eqs. (1), (3), (5) can reach $4 \mathrm{Nm}$, the uncontrollable torque

Table 1 Rheological properties of MR fluids

\begin{tabular}{c|l}
\hline $\begin{array}{c}\text { MRF- } \\
132 \mathrm{D} \\
\mathrm{G}\end{array}$ & $\mu_{0}=0.1 \mathrm{pa} \cdot \mathrm{s} ; \mu_{\infty}=3.8 \mathrm{pa} \cdot \mathrm{s} ; \alpha_{s \mu}=4.5 T^{-1}$ \\
\hline $\begin{array}{c}\mathrm{MRF}- \\
140 \mathrm{C} \\
\mathrm{G}\end{array}$ & $\mu_{0}=15 \mathrm{pa} ; \tau_{y \infty}=40.29 \mathrm{paa} ; \alpha_{s t_{y}}=2.9 T^{-1}$ \\
\hline
\end{tabular}

calculated by Eqs. (2), (4) and (6) are constrained to be smaller than $0.02 \mathrm{Nm}$ and the mass of the MR brakes calculated by Eq. (7) is minimized.

In order to obtain solution of the above optimization problem, firstly the magnetic circuit of the MR brake must be solved. From the magnetic solution, the magnetic flux density across the active MR fluid gap is calculated and the corresponding induced yield stress is determined. Once the induced yield stress of MR fluid is obtained, the braking torque of the MR brakes can be calculated. All the parameters, the zero-field torque, the braking torque and the mass of the MR brakes are then sent to an optimization toolbox for optimization process. In this study, finite element(FE) analysis integrated with the optimization toolbox in ANSYS software is employed and the optimal solutions are obtained by using the first order method with golden section algorithm ${ }^{(15)}$.

\section{Results and Discussion}

In this section, the optimal solutions of the above MR brakes are obtained and presented. In this study, it is assumed that magnetic parts of the brake rotor and stator are made of commercial silicon steel, the coil wires are sized as 21 -gage $($ diameter $=0.511 \mathrm{~mm}) \quad$ whose allowable working current is $2.5 \mathrm{~A}$, the shaft of the brake is made of aluminum and two commercial MR fluids MRF-140-CG and MRF-132-DG made by Lord Corporation are used. It is noted that the rheological properties of the MR fluids depends on the applied magnetic field and can be estimated by the following equation ${ }^{(15,16)}$

$$
Y=Y_{\infty}+\left(Y_{0}-Y_{\infty}\right)\left(2 e^{-B \alpha_{S Y}}-e^{-2 B \alpha_{S Y}}\right)
$$

where $Y$ stands for a rheological parameters of MR fluid such as yield stress and the post yield stress viscosity.

The value of $Y$ tends from the zero applied field value $Y_{0}$ to the saturation value $Y_{\infty} . a_{S Y}$ is 
the saturation moment index of the $Y$ parameter. $B$ is the applied magnetic density. The rheological parameters of MRF-140-CG and MRF-132-DG are experimentally determined and presented in Table 1. It is noteworthy that in order to predict the rheological properties of MR fluid using Eq. (8), the magnetic density across the MR gaps is determined using FE analysis. In this study, the magnetic circuit of the MR brakes is solved using ANSYS software. The FE model of the brake using axisymmetric element(PLANE 13) is shown in Fig. 3. Significant dimensions of the brake are also shown in the figure.

Figure 4 and 5 respectively show the optimization solution of the MR brakes featuring the

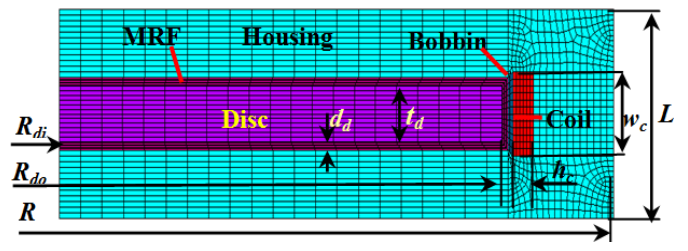

(a) Disc-type MR brake

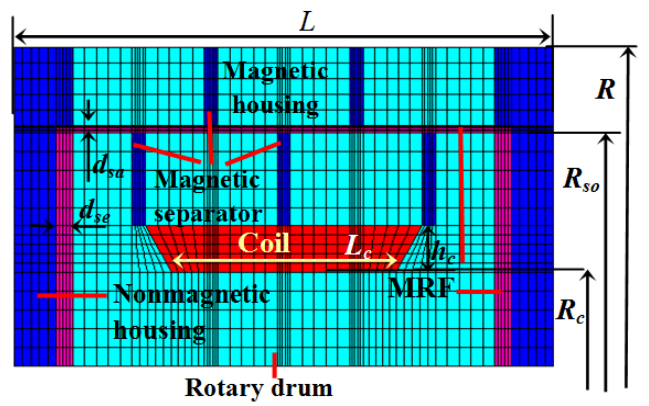

(b) Serpentine MR brake

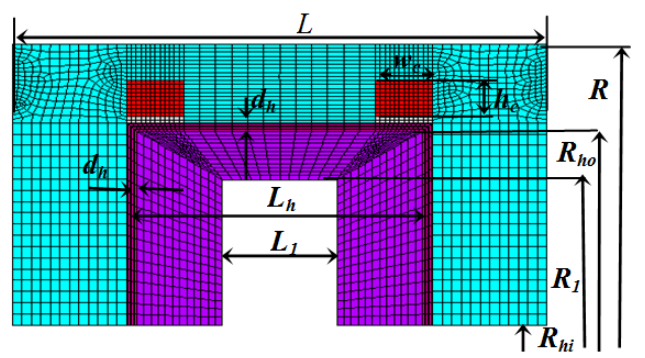

(c) Two-coil hybrid MR brake

Fig. 3 Magnetic finite element model of the MR brakes
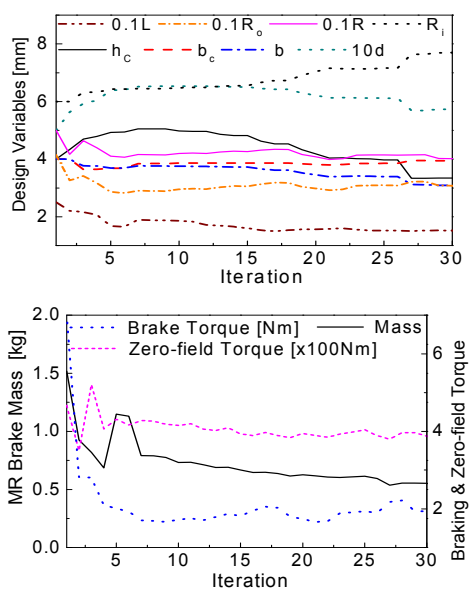

(a) Disc type
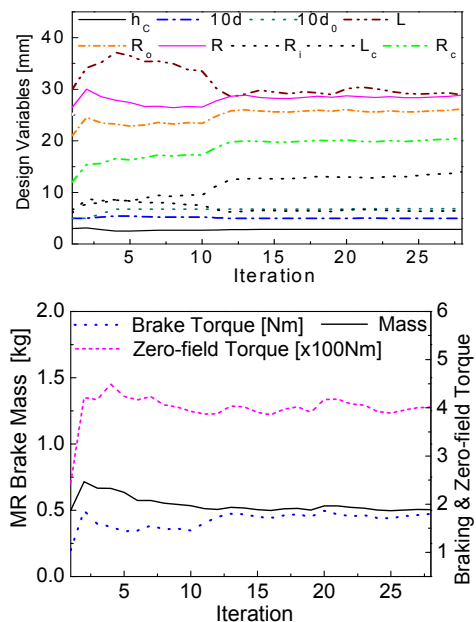

(b) Serpentine type
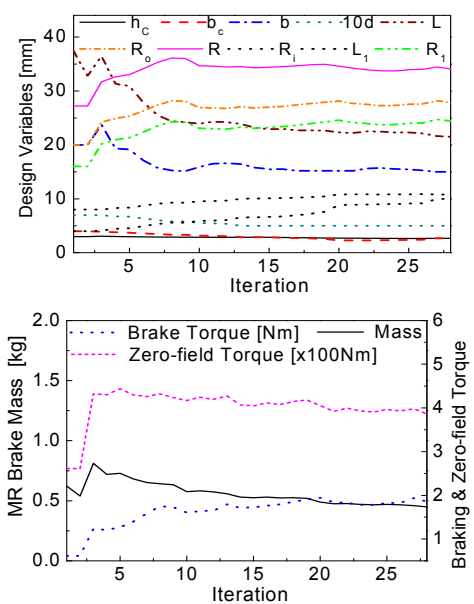

(c) Hybrid type

Fig. 4 Optimization solution of the proposed MR brakes featuring MRF-140-CG 

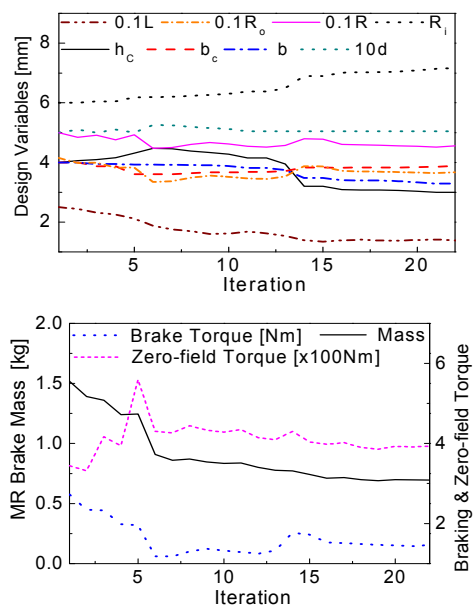

(a) Disc type
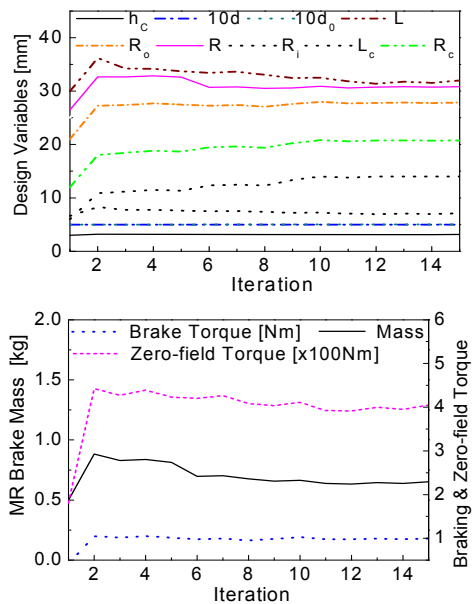

(b) Serpentine type
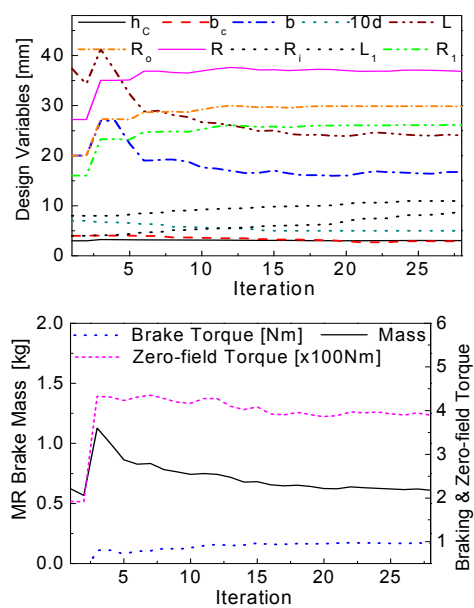

(c) Hybrid type

Fig. 5 Optimization solution of the proposed MR brakes featuring MRF-132-DG high viscosity MR fluid(MRF-140-CG) and the moderate viscosity MR fluid(MRF-1322-DG). The summary of the optimal solution is presented in Table 2. In the table, initial value of parameter is given in brackets. From the results it is found that, in case of using MRF-140-CG, by optimal design, the mass of the hybrid MR brake can reduced as small as $0.46 \mathrm{~kg}$ while that of the disc-type MR brake and the serpentine MR brakes are $0.53 \mathrm{~kg}$ and $0.5 \mathrm{~kg}$, respectively. In case of using MRF-132-DG, at the optimum the mass of

Table 2 Optimal parameters of double

\begin{tabular}{|c|c|c|}
\hline \multirow{2}{*}{ Parameters } & \multicolumn{2}{|c|}{ Optimal value(mm) } \\
\hline & $132 \mathrm{DG}$ & $140 \mathrm{CG}$ \\
\hline \multicolumn{3}{|c|}{ Disc-type MR brakes } \\
\hline $\begin{array}{l}\text { Coil height } h_{c} \\
\text { Coil width } w_{c} \\
\text { Disc thickness } t_{d} \\
\text { End-face duct gap } d_{d} \\
\text { Brake length } L \\
\text { Brake radius } R \\
\text { Disc inner radius } R_{s i} \\
\text { Disc outer radius } R_{s o} \\
\text { Brake mass } m(\mathrm{~kg}) \\
\text { Zero-field torque }(\mathrm{Nm}) \\
\text { Braking torque }(\mathrm{Nm})\end{array}$ & $\begin{array}{l}3.31(4) \\
3.83(4) \\
3.4(4) \\
0.5(0.6) \\
14(25) \\
46(50) \\
7(6) \\
37(41.5) \\
0.71(1.52) \\
0.016(0.03) \\
4(3.4)\end{array}$ & $\begin{array}{l}3.35(4) \\
3.95(4) \\
3(4) \\
0.57(0.6) \\
15.3(25) \\
40.2(50) \\
7.7(6) \\
31(41.5) \\
0.53(1.52) \\
0.02(0.07) \\
4(4.7)\end{array}$ \\
\hline \multicolumn{3}{|c|}{ Serpentine-type MR brakes } \\
\hline $\begin{array}{l}\text { Coil height } h_{c} \\
\text { End-face duct gap } d_{s e} \\
\text { annular duct gap } d_{s a} \\
\text { Brake length } L \\
\text { Brake radius } R \\
\text { Drum inner radius } R_{s i} \\
\text { Drum outer radius } R_{s o} \\
\text { Coil inner radius } R_{c} \\
\text { Coil inner length } L_{c} \\
\text { Nonmagnetic housing } t_{h} \\
\text { Brake mass } m(\mathrm{~kg}) \\
\text { Zero-field torque }(\mathrm{Nm}) \\
\text { Braking torque }(\mathrm{Nm})\end{array}$ & $\begin{array}{l}3.15(3) \\
0.5(0.6) \\
0.5(0.6) \\
32(30) \\
30.8(26.5) \\
14(6) \\
27.8(21) \\
20.7(12) \\
7.1(6.7) \\
2.5(2.5) \\
0.65(0.51) \\
0.01(0.004) \\
4(1.8)\end{array}$ & $\begin{array}{l}2.85(3) \\
0.69(0.6) \\
0.5(0.6) \\
29(30) \\
28.9(26.5) \\
14(6) \\
26.2(21) \\
20.5(12) \\
6.4(6.7) \\
2.5(2.5) \\
0.5(0.51) \\
0.018(0.1) \\
4(2.4)\end{array}$ \\
\hline \multicolumn{3}{|c|}{ hybrid-type MR brakes } \\
\hline $\begin{array}{l}\text { Coil height } h_{c} \\
\text { Coil width } w_{c} \\
\text { Drum thickness } L_{h} \\
\text { End-face duct gap } d_{h} \\
\text { Brake length } L \\
\text { Brake radius } R \\
\text { Drum inner radius } R_{h i} \\
\text { Drum outer radius } R_{h o} \\
\text { Mass removal Radius } R_{1} \\
\text { Mass removal length } L_{1} \\
\text { Brake mass } m(\mathrm{~kg}) \\
\text { Zero-field torque }(\mathrm{Nm}) \\
\text { Braking torque }(\mathrm{Nm})\end{array}$ & $\begin{array}{l}3(3) \\
2.9(4) \\
16.8(20) \\
0.5(0.7) \\
24.3(37.5) \\
37(27) \\
9(4) \\
32.2(20) \\
26(16) \\
11(8) \\
0.62(0.63) \\
0.01(0.026) \\
4(1.9)\end{array}$ & $\begin{array}{l}2.7(3) \\
2.67(4) \\
15(20) \\
0.5(0.7) \\
21.6(37.5) \\
34.4(27) \\
10(10) \\
28.2(20) \\
24.7(16) \\
10.8(8) \\
0.46(0.63) \\
0.02(0.006) \\
4(2.6)\end{array}$ \\
\hline
\end{tabular}


he hybrid MR brake is $0.462 \mathrm{~kg}$ while that of the disc-type MR brake and the serpentine MR brakes are $0.65 \mathrm{~kg}$ and $0.71 \mathrm{~kg}$, respectively. In all cases,

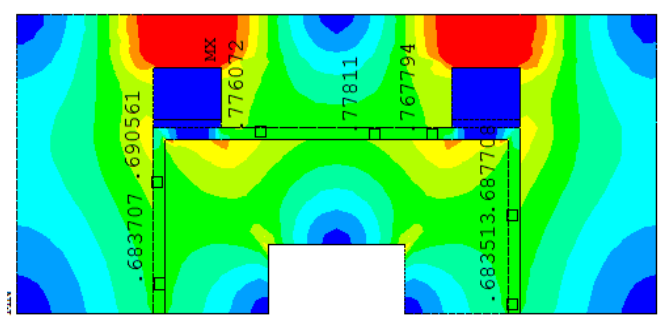

(a) Magnetic flux density

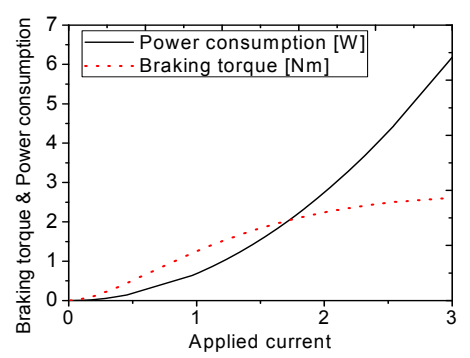

(b) Braking torque, power consumption vs. appliedcurrent

Fig. 6 Characteristics of the initial hybrid MR brake

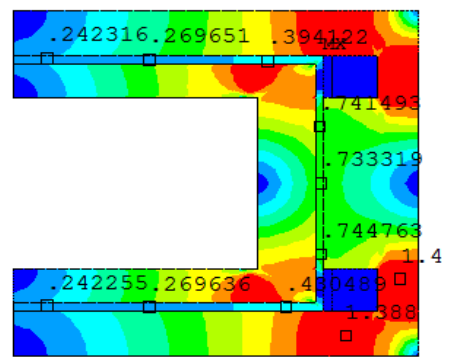

(a) Magnetic flux density

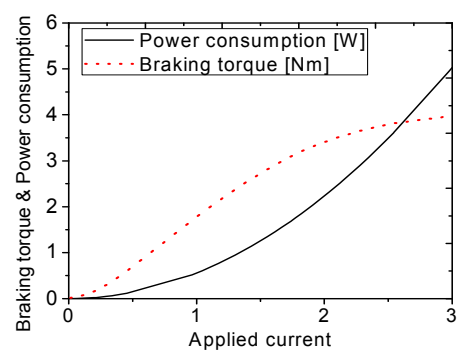

(b) Braking torque, power consumption vs. appliedcurrent

Fig. 7 Characteristics of the optimized MR brake the braking torque can reach up to $4 \mathrm{Nm}$ and the zero-field torque is smaller $0.02 \mathrm{Nm}$. In some cases such as the serpentine and hybrid MR brake featuring MRF-132-DG, the zero-field torque is much smaller than the constrained value, $0.02 \mathrm{Nm}$. The reason is that, in the above optimal design the lower limit of MR fluid gap size is set by $0.5 \mathrm{~mm}$ considering manufacturing cost and ability. Therefore, the gap size of MR brakes cannot be reduced smaller than $0.5 \mathrm{~mm}$ during optimization process. It is also noteworthy that because of its complex structure, the serpentine MR brake is obviously more difficult and costly to manufacture than the hybrid and the disc-type MR brake. From the above, it can be concluded that in order to obtain a braking torque up to 4 $\mathrm{Nm}$ while the zero-field torque is constrained to be very small $(0.02 \mathrm{Nm})$ required for the haptic gripper, the hybrid MR brake featuring MRF-140-CG with the significant dimensions shown in Table 2 is the optimized one. Characteristics of the initial and the optimized hybrid MR brake are shown in Fig. 6 \& 7 respectively.

\section{Conclusion}

In this work, the configuration of a 2-D haptic gripper was proposed. The haptic gripper featuring two MR brakes to reflect rolling torque and the grasping force from a telemanipulator to the master-operator. There types of MR brakes: the disc-type, the serpentine and the hybrid-type were proposed for the haptic. An optimal design of the MR brakes was performed based on FE analysis. In the optimal design, two popular commercial MR fluid(MRF-132-DG and MRF-140-CG) are considered. The optimal results showed that among the proposed MR brakes, the hybrid MR brake featuring MRF-140-CG is the best one. The optimized MR brake weighted $0.46 \mathrm{~kg}$ can generate a braking torque up to $4 \mathrm{Nm}$ while the 
zero-field torque is constrained to be smaller than $0.02 \mathrm{Nm}$. As the second phase of this study, the haptic gripper prototype will be manufactured and its performance will be experimentally evaluated.

\section{Acknowledgement}

This work was supported by the National Research Foundation of Korea(NRF) grant funded by the Korean Government(MEST)(No. 2010-0015090)

\section{References}

(1) Stone, R. J., 2000, Haptic Feedback: a Brief History from Telepresent to Virtual Reality, Proc. 1st International Workshop on Haptic Human-computer Interaction LNCS 2085, pp. 1 16.

(2) Lemoine, P., Gutierrez, M., Vexo, F. and Thanmann, D., 2004, Mediators: Virtual Interfaces with Haptic Feedback, Proc.EuroHaptics, Munich, Germany, pp. 68 73.

(3) Gupta, A. and O'Malley, M. K., 2006, Design of a Haptic Arm Exoskeleton for Training and Rehabilitation, IEEE-ASME Transactions on Mechatronics, Vol. 11, No. 3, pp. 280 289.

(4) Alan, S. and Marcia, K. O., 2006, Performance Enhancement of a Haptic Arm Exoskeleton, Haptics, International Symposium on Haptic Interfaces for Virtual Environment and Teleoperator Systems.

(5) Chapuis, D., et al., 2010, ReFlex, a Haptic Wrist Interface for Motor Learning and Rehabilitation, IEEE Haptics Symposium, pp. 417 424.

(6) Nguyen, Q. H. and Choi, S. B., 2011, Optimal Design of a Hybrid MR Brake for Haptic Wrist Application, Proc. SPIE, Vol. 7977, No. 1, pp. 7977 18-.

(7) Blake, J. and Gurocak, H. B., 2009, Haptic Glove With MR Brakes for Virtual Reality, IEEE-ASME Transactions on Mechatronics, Vol. 14,
No. 5 pp. $606 \sim 615$.

(8) Winter, S. H. and Bouzit, M., 2007, Use of Magnetorheological Fluid in a Force Feedback Glove, IEEE Transactions on Neural Systems and Rehabilitation Engineering, Vol. 15, No. 1, pp. 2 8.

(9) Bullion, C. and Gurocak, H., 2009, Haptic Glove with MR Brakes for Distributed Finger Force Feedback, Presence-Teleoperators and Virtual Environments, Vol. 18, No. 6, pp. 421 433.

(10) Ferre, M., Galiana, I., et al., 2011, Haptic Device for Capturing and Simulating Hand Manipulation Rehabilitation, IEEE-ASME Transactions on Mechatronics, Vol. 16, No. 5, pp. 808 815.

(11) Johnsson, M. and Balkenius, C., 2006, Experiments with Artificial Haptic Perception in a Robotic Hand, Journal of Intelligent \& Fuzzy Systems, Vol. 17, No. 4, pp. 377 385.

(12) Kawasaki, H. and Mouri, T., 2007, Design and Control of Five-fingered Haptic Interface Opposite to Human Hand, IEEE Transactions on Robotics, Vol. 23, No. 5, pp. 909 918.

(13) Kang, P. S., Han, Y. M. and Choi, S. B., 2006, Force-feedback Control of an Electrorheological Haptic Device in MIS Virtual Environment, Transactions of the Korean Society for Noise and Vibration Engineering, Vol. 16, No. 12, pp. 1286 1293.

(14) Senkal, D. and Gurocak, H., 2009, Compact MR-brake with Serpentine Flux Path for Haptics Applications, World Haptics Conference, pp. 91 96.

(15) Nguyen, Q. H. and Choi, S. B., 2010, Optimal Design of an Automotive Magnetorheological Brake Considering Geometric Dimensions and Zero-field Friction Heat, Smart Matter. Struct. Vol. 19, No. 11, pp. 1 11.

(16) Zubieta, M., Eceolaza, S., Elejabarrieta, M. J. and Bou-Ali, M. M., 2009, Magnetorheological Fluids: Characterization and Modeling of Magnetization, Smart Matter. Struct., Vol. 18, pp. 1 6. 